\title{
Residência Médica e Produção de Conhecimento
}

Family Medicine Residency and Research

\section{Senhor Editor}

Em recente artigo publicado na Revista Brasileira de Medicina de Família e Comunidade, Anderson et al. ${ }^{1}$ apresentam um excelente artigo que, de forma didática e objetiva, serve como guia para a estruturação de Programas de Residência Médica (PRM) em Medicina de Família e Comunidade (MFC).

Estamos vivendo um saudável período de rápida expansão de programas de residência em MFC, em que nem sempre as instituições proponentes possuem grande experiência na área, tanto na especialidade em si quanto na formação pós-graduada. Sem pretender uma desnecessária uniformização dos PRMs, propostas de sistematização como essa, que detalham em termos práticos as resoluções da Comissão Nacional de Residência Médica (CNRM), são extremamente bem-vindas, constituindo-se uma fonte valiosa para esse público, felizmente cada vez mais numeroso em nosso país.

Senti falta, contudo, de um elemento que considero fundamental e estratégico durante a residência médica: a investigação científica. Ainda que haja citações - muito genéricas e quase despercebidas - sobre "produção científica" e "trabalho de final de curso", a palavra "pesquisa" não aparece uma única vez em todo o documento.

A necessidade de realizar pesquisa nos PRMs é um tema que já vem sendo discutido em outros países há mais tempo e que, na minha opinião, necessita ser introduzida urgentemente no Brasil.

Em artigo publicado em 1998, DeHaven $e t$ al. ${ }^{2}$, embora reconhecesse a falta de tradição na especialidade, já sustentava a importância da inclusão do treinamento em pesquisa nos programas de residência médica.

Artigos publicados nos anos seguintes reforçam essa posição a ponto de um documento publicado em 2004 em nome da American Academy of Family Physicians afirmava que "mais pesquisa é uma necessidade para orientar uma revisão séria da própria medicina de família"

Esse parece ser um apelo claro no sentido de consolidar a MFC como especialidade médica com status científico no mesmo nível das demais especialidades, ganhando, portanto, respeito e credibilidade frente aos pacientes, aos estudantes e aos círculos acadêmicos. Além disso, essa necessidade se dá pela nítida carência de produção de conhecimento numa área em que, infelizmente, ainda adaptamos (frequentemente de forma acrítica) a produção científica gerada em contextos clínicos totalmente diferentes da Atenção Primária à Saúde (APS) e onde esse conhecimento deve ser aplicado 4 .

Como médicos de família e comunidade, precisamos estar abertos à experimentação, colocando toda a nossa criatividade em favor de uma "cultura de inovação"3 que represente, em última análise, melhorias da saúde dos nossos usuários e de suas comunidades. Essa provocação implica, sobretudo, sermos capazes de questionar a nossa própria especialidade e a forma como a praticamos. 
Parece óbvio, entretanto, que esse debate não se limita à medicina de família, mas expande-se para todos os campos de conhecimento que compõem a APS. Além disso, os Programas de Residência Médica (e multiprofissional) são locais privilegiados para iniciar essa transformação. Os cenários das Unidades Básicas de Saúde e suas comunidades, com a sua imensa variedade de complexas situações cotidianas são um campo riquíssimo para problematizarmos questões relacionadas ao processo saúde/doença, assim como propostas de prevenção e promoção de saúde. De fato, quando essas oportunidades são bem aproveitadas, os resultados tendem a ser altamente satisfatórios. Smith ${ }^{5}$, estudando egressos de PRMs em medicina de família no Estado norte-americano de Michigan, mostrou que a simples inclusão de temas sobre pesquisa no currículo favoreceu atitudes positivas acerca de pesquisa, apesar de não formar necessariamente pesquisadores.

Esse não deve ser o objetivo dos PRMs. Eles devem formar bons médicos especialistas, reservando a formação de pesquisadores para os programas de pós-graduação lato sensu. O que defendo é que um médico-residente pode e deve desenvolver mecanismos iniciais para, olhando a realidade ao seu redor, formular boas perguntas que possam ser materializadas em bons projetos de pesquisa. Ou seja, ser capaz de responder de forma sistemática (por meio de uma metodologia quali ou quantitativa) aos questionamentos originados do seu cotidiano.

Essa é uma habilidade fundamental a ser desenvolvida e não há melhor momento para isso do que o ambiente protegido das residências médicas.

Com certeza, uma base sólida em pesquisa favorecerá uma prática profissional mais segura, permitindo análises aprofundadas das evidências oriundas de outros estudos publicados, uma habilidade cada vez mais valorizada no mundo atual.

No Brasil, a implantação da Estratégia de Saúde da Família já mostrou um aumento perceptível nas pesquisas na área ${ }^{6}$. Um aspecto a ser enfrentado refere-se não apenas à quantidade de artigos, mas também à qualidade deles, um problema que não é exclusivo do Brasil. Um estudo publicado em 2003, analisando artigos publicados em periódicos de prestígio na especialidade nos Estados Unidos, evidenciou que a maioria dos artigos usava delineamentos com menor rigor científico, não atingindo critérios estabelecidos de relevância e validade?

Assim, podemos dizer que os desafios atuais são enormes, especialmente num momento em que buscamos compatibilizar os grandes avanços tecnológicos com a necessidade de maior humanização do cuidado.

Voltando a DeHaven², o seu estudo já demonstrava algumas características ainda atuais e que talvez mereçam ser trabalhadas pelos Programas de Residência Médica de MFC no Brasil. Resumidamente, são elas:

1. existência de um supervisor do programa que seja comprometido e que ofereça apoio à ideia de envolver os residentes em pesquisa;

2. disponibilidade de tempo suficiente no Programa para pesquisa - a Resolução CNRM $n^{\circ}$ 02/2006 prevê atividades na área do ensino e da pesquisa, sem, contudo, estabelecer carga horária mínima ${ }^{8}$;

3. envolvimento dos preceptores em pesquisa;

4. montagem de um currículo que inclua treinamento básico sobre pesquisa e leitura crítica de artigos científicos (clube de revista);

5. acesso facilitado a profissionais de outras áreas do conhecimento: ciências sociais, estatística, epidemiologia etc.;

6. oportunidades para apresentação dos resultados das pesquisas, tanto para o público interno como para as comunidades e público acadêmico, congressos e salões de pesquisa.

Francisco Arsego de Oliveira

Departamento de Medicina Social - Faculdade de Medicina da Universidade Federal do Rio Grande do Sul (UFRGS)

Programa de Residência Médica em Medicina de Família e Comunidade - Hospital de Clínicas de Porto Alegre

Rua Ramiro Barcelos, 2.350

CEP: 90035-903 Porto Alegre (RS), Brasil

E-mail: farsego@hcpa.ufrgs.br 


\section{Referências}

1. Anderson MIP, Castro Filho ED, Rodrigues RD, Dalla MDB, Bourget MMM. Bases para a expansão e desenvolvimento adequados de programas de residência em Medicina de Família e Comunidade. Rev Bras Med Fam Com. 2007;3(11):180-98.

2. DeHaven MJ, Wilson GR, O'Connors-Hettlestrines P. Creating a research culture: what we can learn from residencies that are successful in research. Fam Med. 1998;30(7):501-7.

3. Future of Family Medicine Project Leadership Committee. The future of family medicine: a collaborative project of the family medicine community. Ann Fam Med. 2004;2(suppl 1):S3-S32.

4. Van Weel C. Research in Primary care: how to live-up to its needs. Primary health care Research and Development. 2007:8-12 (editorial).

5. Smith M. Research in residency: do research curricula impact post-residency practice? Fam Med. 2005;37(5):322-7.

6. Harzheim E, Stein AT, Álvarez-Dardet C, Cantero MTR, Kruse CK, Vidal TB, et al. Revisão sistemática sobre aspectos metodológicos das pesquisas em atenção primária no Brasil. Revista da AMRIGS. 2005;49(4):248-52.

7. Merenstein J, Rao G, D’Amico F. Clinical research in Family Medicine: quantity and quality of published articles. Fam Med. 2003;35(4):284-8.

8. Brasil. Ministério da Educação. Secretaria de Ensino Superior. Resolução CNRM n 02/2006.

\section{Resposta: Maria Inez Padula Anderson}

Muito bem-vindas as considerações de Francisco Arsego. De fato, é bastante importante e relevante que os espaços de ensino-aprendizagem no âmbito da Medicina de Família e Comunidade (MFC) e Atenção Primária a Saúde (APS) sejam, também, ambientes de reflexão e avaliação sistemática sobre o trabalho e a produção de conhecimento ${ }^{1}$. No caso do artigo publicado, ele foi baseado em um documento escrito em 2005, por iniciativa da Sociedade Brasileira de Medicina da Família e Comunidade (SBMFC), para colaborar com o movimento de expansão dos Programas de Residência em Medicina de Família e Comunidade (PRMFC) no Brasil, por incentivo do Ministério da Saúde. O objetivo central, naquele momento, era subsidiar, de forma premente e urgente, os diversos serviços interessados em iniciar um PRMFC, considerando a insuficiência quantitativa de aparelho formador na área da MFC. Dessa forma, e com o tempo técnico e político disponível nesse contexto, foi necessário focar nos aspectos mais estruturantes, especialmente as competências (conhecimentos, habilidades e atitudes), além da questão da preceptoria, da distribuição da carga horária nas atividades centrais e organização do processo de trabalho. Não houve tempo, à época, para detalhar os conteúdos dos temas das atividades teóricas, nem tampouco, a questão da pesquisa, que no caso da Residência Médica, se aprofunda e concretiza, não somente, mas principalmente, na forma do trabalho de conclusão de curso.

Passados quatro anos, em outro momento do processo, podemos galgar outros patamares. Nesse sentido, uma reunião da Diretoria Científica com os Diretores de formação da SBMFC, apontou, exatamente, para a necessidade de revisão daquele documento, visando a seu aperfeiçoamento e inclusão e detalhamento destes e outros aspectos. O único cuidado é não superdimensionar a produção de pesquisa num programa de treinamento em serviço, função primordial de um PRM. De toda forma, a SBMFC e suas estaduais têm incentivado a produção de pesquisa pelos residentes, para apresentação e premiação em congressos da entidade e/ou apoiando ida a eventos nacionais e internacionais. Também, incentivando a elaboração de artigos para a RBMFC. Mais recentemente, a opção e possibilidades abertas pela iniciativa do MS, de abrir mestrados profissionalizantes "em parceria" com os PRM, inclusive em MFC, abrem novos horizontes. A SBMFC e os PRMFC mais consolidados têm grande contribuição a dar nesse campo.

\section{Referências}

1. Anderson MIP, Castro Filho ED, Rodrigues RD, Dalla MDB, Bourget MMM. Bases para a expansão e desenvolvimento adequados de programas de residência em Medicina de Família e Comunidade. Rev Bras Med Fam Com. 2007;3(11):180-98. 